\title{
Methylated genes as new cancer biomarkers
}

Brunner, Nils; Duffy, M.J; Napieralski, R.; Martens, J.W.M. ; Span, P.N. ; Spyratos, F.; Sweep, F.C.G.J.; Foekens, J.A. ; Schmitt, M.

Published in:

European Journal of Cancer

DOI:

10.1016/j.ejca.2008.12.008

Publication date:

2009

Document version

Early version, also known as pre-print

Citation for published version (APA):

Brunner, N., Duffy, M. J., Napieralski, R., Martens, J. W. M., Span, P. N., Spyratos, F., Sweep, F. C. G. J.,

Foekens, J. A., \& Schmitt, M. (2009). Methylated genes as new cancer biomarkers. European Journal of Cancer, 45(3), 335-346. https://doi.org/10.1016/j.ejca.2008.12.008 


\title{
Position Paper
}

\section{Methylated genes as new cancer biomarkers}

\author{
M.J. Duffy ${ }^{a, b, *}$, R. Napieralskic, J.W.M. Martens ${ }^{d}$, P.N. Span ${ }^{e}$, F. Spyratos ${ }^{f}$, F.C.G.J. Sweep ${ }^{e}$, \\ N. Brunner ${ }^{g}$, J.A. Foekens ${ }^{d}$, M. Schmitt ${ }^{c}$, on behalf of the EORTC PathoBiology Group \\ ${ }^{a}$ Department of Pathology and Laboratory Medicine, Nuclear Medicine Laboratory, St. Vincent's University Hospital, \\ Elm Park, Dublin 4, Ireland \\ ${ }^{\mathrm{b}} \mathrm{UCD}$ School of Medicine and Medical Science, Conway Institute of Biomolecular and Biomedical Research, University College Dublin, \\ Dublin, Ireland \\ ${ }^{c}$ Department of Obstetrics and Gynecology, Frauenklinik der Technischen Universitaet München, Klinikum rechts der Isar, Munich, Germany \\ dDepartment of Medical Oncology, Erasmus MC, Rotterdam, The Netherlands \\ eDepartment of Chemical Endocrinology, Radboud University Nijmegen Medical Centre, Nijmegen, The Netherlands \\ ${ }_{\mathrm{f}}^{\mathrm{Laboratoire}}$ d'Oncogenetique, Centre Rene Huguenin, St-Cloud, France \\ 'section of Biomedicine, Department of Veterinary Pathobiology, Faculty of Life Sciences, University of Copenhagen, Frederiksberg, Denmark
}

\section{A R T I C L E I N F O}

Article history:

Received 1 October 2008

Received in revised form 5

December 2008

Accepted 12 December 2008

Available online 12 January 2009

Keywords:

Gene methylation

Cancer

Biomarkers

Tumour markers

Pathobiology group

EORTC

\begin{abstract}
A B S T R A C T
Aberrant hypermethylation of promoter regions in specific genes is a key event in the formation and progression of cancer. In at least some situations, these aberrant alterations occur early in the formation of malignancy and appear to be tumour specific. Multiple reports have suggested that measurement of the methylation status of the promoter regions of specific genes can aid early detection of cancer, determine prognosis and predict therapy responses. Promising DNA methylation biomarkers include the use of methylated GSTP1 for aiding the early diagnosis of prostate cancer, methylated PITX2 for predicting outcome in lymph node-negative breast cancer patients and methylated MGMT in predicting benefit from alkylating agents in patients with glioblastomas. However, prior to clinical utilisation, these findings require validation in prospective clinical studies. Furthermore, assays for measuring gene methylation need to be standardised, simplified and evaluated in external quality assurance programmes. It is concluded that methylated genes have the potential to provide a new generation of cancer biomarkers.
\end{abstract}

(c) 2008 Elsevier Ltd. All rights reserved.

\section{Introduction}

Tumour biomarkers are potentially useful in the identification of individuals at increased risk of developing cancer, in screening for early malignancies and in aiding cancer diagnoses. Following a diagnosis of cancer, biomarkers may be used for determining prognosis, predicting therapeutic response, sur- veillance following curative surgery for cancer and monitoring therapy (for review, see Refs. [1,2]). Currently used tumour markers are mostly proteins that are measured in either serum or plasma (e.g. by sandwich-type immunoassay) or in tumour tissue (e.g. by ELISA or immunohistochemistry). ${ }^{1,2}$

The primary defect in cancer resides in genomic DNA. Molecular alterations in DNA that contribute to cancer

\footnotetext{
* Corresponding author: Address: Department of Pathology and Laboratory Medicine, Nuclear Medicine Laboratory,

St. Vincent's University Hospital, Elm Park, Dublin 4, Ireland. Tel.: +353 1 2094378; fax: +353 12696018.

E-mail address: Michael.J.Duffy@ucd.ie (M.J. Duffy).

0959-8049/\$ - see front matter @ 2008 Elsevier Ltd. All rights reserved.

doi:10.1016/j.ejca.2008.12.008
} 
include mutation, amplification, translocation, loss of heterozygosity, microsatellite instability and aberrant gene methylation. ${ }^{3,4}$ Specific genes with such abnormalities have been suggested as potential new tumour biomarkers. ${ }^{5,6}$

Compared with other molecular structures such as mRNA, miRNA and certain proteins, the use of DNA for the measurement of tumour marker has a number of attractive features. ${ }^{7}$ Firstly, DNA molecules are very stable and in contrast to mRNA and many proteins, can survive harsh conditions for long periods of time. Most importantly, relatively intact DNA can be isolated from formalin-fixed, paraffin-embedded tissue. Secondly, unlike proteins, nucleic acid can be amplified by PCR and related techniques, thus allowing measurements on small amounts of test sample. The aim of this article is to review the use of one form of DNA alteration in cancer, i.e. aberrant gene promoter methylation, for the detection and management of patients with cancer. Firstly, however, a brief introduction to DNA methylation is presented.

\section{DNA methylation}

DNA methylation involves the substation of a hydrogen ion with a methyl group at the carbon 5 position of cytosine (C) residues, using S-adenosylmethionine as the donor molecule (for review, see Refs. [8,9]). In mammalian cells, methylation is mostly restricted to $C$ residues that proceed guanine $(G)$ residues, i.e. CpG dinucleotides. In general, the CpG dinucleotide is underrepresented in the mammalian genome but it can be found at relatively high frequency in short genomic sequences, known as CPG islands.

CpG islands range in size from 0.5 to $5 \mathrm{~kb}$, and have a G:C content of at least $55 \%$ and an CpG to GpC frequency of at least $0.65 .{ }^{10} \mathrm{CpG}$ islands are associated with approximately $50 \%$ of mammalian genes and are mostly located in the promoter and first exon regions of the gene, although occasionally they are also found towards the $3^{\prime}$ end. ${ }^{8} \mathrm{CpG}$ islands are mostly unmethylated in normal adult healthy tissues, but can be methylated to varying extents in cancer. ${ }^{11}$ Methylation of CpG islands in gene promoter regions is generally associated with gene silencing due to the abrogation of gene transcription. ${ }^{8,9}$

Genomic scanning of 98 different primary tumours showed that on average, there were approximately 600 aber- rantly methylated genes per tumour. ${ }^{12}$ Indeed, genes implicated in most of the steps in tumourigenesis and tumour progression can be silenced by DNA promoter methylation. ${ }^{12,13}$ These genes include not only those encoding proteins, but also those coding for microRNAs. ${ }^{8,9}$

The genes undergoing methylation during the early phases of tumourigenesis are potential markers for identifying individuals at increased risk of developing malignancy or for aiding the diagnosis of early malignancy, while those genes undergoing methylation during progression of malignancy are potential prognostic markers. In addition, measurement of the methylation status of genes involved in drug sensitivity and/or resistance may yield therapy predictive information.

\section{Advantages of using methylated genes as tumour biomarkers}

Blood levels of most currently used protein biomarkers are rarely increased in the early stage malignancy. ${ }^{1}$ Consequently, most existing blood protein biomarkers are of little value in either screening or aiding the early diagnosis of cancer. On the other hand, aberrant methylation of the promoter regions of multiple genes is now known to exist in both early and advanced cancers (Table 1). Release of cells or free DNA containing these aberrantly methylated genes into surrounding luminal fluids or blood might thus permit the early detection of cancer or the identification of individuals at high risk of developing cancer. Some of the advantages of using methylated genes as cancer markers are now briefly discussed.

\subsection{Serum concentrations of methylated genes display a high specificity for malignancy}

In contrast to the existing biomarkers, methylated genes appear to have superior specificity for cancer. In a review of the early literature, Laird $^{10}$ identified 599 hypermethylated $\mathrm{CpG}$ islands in serum or plasma from 325 independent control subjects. Remarkably, all were found to be negative for the DNA methylation biomarkers investigated, yielding an overall specificity of $100 \%$. Lower specificity, however, was found when DNA methylation analysis was carried out on the relevant luminal fluids from these subjects. ${ }^{10}$ As pointed out by

\begin{tabular}{|c|c|c|c|}
\hline Methylated gene & Preneoplastic lesion & Cancer type & Refs. \\
\hline$p 16^{\text {INK4A }}$ & Barrett's esophagus & Oesophageal cancer & {$[14,15]$} \\
\hline$p 16^{\mathrm{INK} 4 \mathrm{~A}}$ & In situ squamous cell carcinoma of lung & Squamous cell lung cancer & {$[16,17]$} \\
\hline$p 16^{\mathrm{INK} 4 \mathrm{~A}}$ & In situ squamous cell carcinoma of cervix & Squamous cell carcinoma of cervix & [18] \\
\hline $\mathrm{p} 16^{\mathrm{INK} 4 \mathrm{~A}}, p 14^{\mathrm{ARF}}, \mathrm{MGMT}, \mathrm{APC}$ & Colorectal adenoma & Colorectal cancer & {$[19,20]$} \\
\hline hMLH1 & Ulcerative colitis & Colorectal cancer & [21] \\
\hline hMLH1 & Endometrial hyperplasia & Endometrial cancer & [22] \\
\hline GSTP1 & HGPIN & Prostate cancer & {$[23,24]$} \\
\hline APC, DAPK, MGMT & Cirrhotic liver & Hepatocellular cancer & [25] \\
\hline 14-3-3 sigma, RASSF1, APC, DAPK & Atypical hyperplasia, DCIS & Breast cancer & [26-28] \\
\hline DAPK1, RARB, TWIST1 & CIN-3 & Cervical cancer & [29] \\
\hline
\end{tabular}


Laird, ${ }^{10}$ this lower specificity may be more apparent than real as the DNA methylation markers may be detecting malignancy earlier than is possible with conventional diagnostic modalities. Alternatively, the presence of DNA methylation biomarkers in luminal fluids may reflect premalignant conditions that have not yet progressed to a cancer that is detectable with existing diagnostic modalities. In such a scenario, quantitative serial levels of the DNA methylation markers may identify preneoplastic lesions that are likely to progress to invasive malignancy. ${ }^{10}$

The high cancer specificity of methylated genes present in blood or in other biological fluids is highly desirable if these markers are to be used in screening for early malignancy. False positive findings are relatively common with existing screening procedures, leading to follow-up testing that does not necessarily result in the diagnosis of cancer. ${ }^{30}$ Such follow-up tests are costly and cause considerable mental stress to the subjects concerned..$^{30}$ Highly specific DNA methylation markers might thus be combined with highly sensitive tests in order to screen for cancer, e.g. in combination with PSA for prostate cancer screening, in combination with CA 125 for ovarian cancer screening or in combination with mammography for breast cancer screening, i.e. panels of tests may be more useful in screening than single tests.

\subsection{Certain genes exhibit relative tissue specificity in their methylation pattern}

Organ specificity is another desirable feature of a tumour biomarker, especially when used in the diagnostic setting. At present, the only widely used organ-specific marker is PSA, which for all practical purposes is prostate specific in man but not prostate cancer-specific. For reasons that are not yet clear, some genes possess significant tissue specificity in their promoter methylation patterns. Thus, the hMLH1 gene is methylated in colorectal ${ }^{31}$ and gastric cancers ${ }^{32}$ but is apparently rarely methylated in oesophageal cancer ${ }^{33}$ and hepatoma, ${ }^{34}$ BRCA1 is methylated in breast and ovarian cancers but not in many other types of cancer ${ }^{35}$, while methylation of the $p 73$ and $p 15^{\text {INK4B }}$ genes appears to be present almost exclusively in haematological malignancies. ${ }^{35}$ If confirmed with larger studies, DNA methylation patterns might be able to help with the identification of metastatic tumours of unknown primary origin. Indeed, following systematic profiling of DNA methylation patterns in a range of different tumour cell lines, Paz et al. ${ }^{36}$ were able to identify a specific profile of CpG islands for each cancer type. It should be stated, however, that not all genes undergoing promoter methylation display organ specificity. For instance, methylation of the RASSF1 and $p 16^{\text {INK4A }}$ (also known as CDKN2A) gene promoters is found in several types of cancer. ${ }^{8,9}$

\subsection{Gene methylation is associated with defined DNA regions}

Unlike the situation with mutations in many cancer-associated oncogenes and tumour suppressor genes, gene promoter methylation in tumours is usually found in confined genomic regions. Consequently, one set of primers can be used to detect the presence of a specific methylated gene. In contrast, mutations in cancer-causing genes such as p53 and APC are distributed over multiple sites, ${ }^{37,38}$ thus requiring many different sets of primers that add to assay complexity and expense. This lack of requirement for multiple sets of primers for DNA methylation measurements simplifies assays design and reduces expense.

\section{Use of methylated genes as tumour biomarkers}

\subsection{Identification of subjects at high risk of developing cancer and aiding early detection of cancer}

In order to be of value in identification of patients at increased risk of cancer, screening or aiding early diagnosis of cancer, a marker should be detectable in a biological sample that can be obtained using a minimally invasive procedure. In addition, alterations in the marker should be specific for the relevant premalignant condition or malignancy and should be measurable in patients with early stage cancer or those with premalignant lesions at high risk of progressing to malignancy.

As shown in Table 2, methylated genes released from tumour tissue can be assayed in a variety of biological fluids. ${ }^{27,39-56}$ The measurement of the methylated genes in these fluids for the identification of subjects at high risk of developing cancer as well as aiding the detection of early malignancy is discussed below.

Table 2 - Biological fluids and tissues in which cancer-derived methylated genes have been shown to have potential diagnostic value.

\begin{tabular}{|c|c|c|c|}
\hline Fluid/tissue & Cancer type & Methylated gene(s) & Refs. \\
\hline Sputum & Lung & $p 16^{\mathrm{INK} 4 \mathrm{~A}}, \mathrm{RASSF} 1, \mathrm{MGMT}$ & {$[27,39-41]$} \\
\hline Ejaculate & Prostate & GSTP1 & {$[42-45]$} \\
\hline Urine & Prostate & GSTP1, RASSF1A, RARß2, APC & {$[46,47]$} \\
\hline Biopsy & Prostate & GSTP1, RARß2, APC, TIG1 & {$[48,49]$} \\
\hline Nipple fluid & Breast & RASSF1 & [50] \\
\hline Serum & Breast & RASSF1, APC, DAPK & {$[28]$} \\
\hline Serum & Ovary & BRCA1, RASSF1 & [51] \\
\hline Peritoneal & Ovary & BRCA1, RASSF1 & [51] \\
\hline Stools & Colorectum & SFRP2, CDKN2A, hMLH1 & {$[52,53]$} \\
\hline Serum & Colorectum & SEPT9, TMEEF2, NGFR & [54] \\
\hline Urine & Bladder & RASSF1 APC, $p 14^{\mathrm{ARF}}, \mathrm{DAPK}, \mathrm{BCL} 2, \mathrm{TERT}$ & {$[55,56]$} \\
\hline
\end{tabular}




\subsubsection{Lung cancer}

Despite many attempts, the development of a clinically useful protein biomarker for lung cancer has remained elusive. Existing protein biomarkers for this disease such as CYFRA 21-1, neurone-specific enolase (NSE) and CEA lack sensitivity and specificity and consequently, they are of little value for early detection. ${ }^{57,58}$ One of the most frequent molecular defects in lung cancer is promoter hypermethylation of several genes (for review, see Ref. [39]). Amongst the genes shown to be hypermethylated in this malignancy are methylguanine methyl transferase (MGMT), p16 ${ }^{\text {INK4A }}$, RASSF1A, APC, CHD13 and RAR $\beta .^{39}$ As some of these genes (e.g. $p 16^{\text {INK4A }}$ ) undergo hypermethylation during the early phases of lung carcinogenesis and can be detected in cells exfoliated into surrounding luminal fluids, they are potential markers for the early detection of lung cancer.

In one of the first studies to investigate the use of DNA methylation markers for the early detection of lung cancer, Palmisano et al. $^{40}$ found hypermethylation of either the $p 16^{\text {INK4A }}$ or the MGMT gene in sputum in all 21 patients with squamous cell carcinoma of the lung (SCCL). For 11/21 patients, sputum samples were obtained 5-36 months prior to the diagnosis of SCCL. In all these 11 patients, hypermethylation of $p 16^{\mathrm{INK} 4 \mathrm{~A}}$ was found, the longest lead-time being 35 months. Apart from one patient with equivocal findings, sputum cytology was not diagnostic. In contrast to patients with SCC, methylation of $p 16^{\mathrm{INK} 4 \mathrm{~A}}$ and MGMT was present in only $15 \%$ and $25 \%$, respectively, of 123 controls without clinical evidence of lung cancer. These controls, however, were at increased risk of developing malignancy because of either cigarette smoking or exposure to radon.

Kersting et al. ${ }^{41}$ also found hypermethylation of the $p 16^{\text {INK4A }}$ gene promoter in sputum from subjects at increased risk of developing lung cancer, i.e. in chronic smokers. While the $p 16^{\text {INK4A }}$ gene was hypermethylated in $18 / 51$ (35\%) of patients with lung cancer, hypermethylation was also found in $4 / 25(16 \%)$ chronic smokers. Interestingly, three of these chronic smokers later developed malignancy. In this study, a higher frequency of $p 16^{\mathrm{INK} 4 \mathrm{~A}}$ gene methylation was detected in sputum from both the lung cancer patients and the chronic smokers than in either bronchial lavage fluid or brushings from these subjects.

In a further study on lung cancer, hypermethylation of the RASSF1A gene promoter was found in sputum from $4 / 8$ (50\%) patients with small cell lung cancer, 5/24 (21\%) in those with non-small cell lung cancer, 4/13 (31\%) chronic smokers, one of the two former smokers but in none of six never smokers. ${ }^{27}$ Significantly, 2/4 of the current smokers and the one former smokers displaying RASSF1A hypermethylation developed lung cancer within 12-14 months of the sputum sampling.

These studies, when taken together, suggest that measurement of DNA methylation markers in sputum is a promising approach for the early detection of lung cancer in subjects at high risk of developing this disease.

\subsubsection{Prostate cancer}

Although controversial, PSA is widely used in screening for prostate cancer. Indeed, elevated serum levels of PSA are now the most common initial event leading to the diagnosis of prostate cancer. ${ }^{59}$ Because of limited specificity and sensitivity, PSA, however, is a non-ideal screening test for prostate cancer. ${ }^{60} \mathrm{~A}$ frequent molecular alteration in prostate cancer is hypermethylation in the promoter region of the glutathioneS-transferase P1 (GSTP1) gene. According to Goessl et al., ${ }^{43}$ GSTP1 promoter hypermethylation constitutes an ideal DNA-based biomarker for prostate cancer because it is present in up to $90 \%$ of prostatic cancer tissues and in $2 / 3$ of high grade prostatic intraepithelial neoplasias (PIN) but is apparently rarely present in benign prostate tissue.

Suh et $a{ }^{45}$ were one of the first to show the potential of this methylated gene for the early detection of prostate cancer. Using ejaculates, these investigators found methylated GSTP1 in 4/9 patients with prostate cancer. Later, Goessl et al. $^{42}$ reported the presence of methylated GSTP1 in 23/32 $(72 \%)$ of sera, in $4 / 8(50 \%)$ of ejaculates and in $4 / 11$ (36\%) urine samples from patients with prostate cancer. In contrast, methylated GSTP1 was not detected in any body fluid investigated from 26 control patients with benign prostate hypertrophy (BPH). In an update of this work, the sensitivity of GSTP1 was found to be $73 \%$, when urine was collected following prostatic massage. ${ }^{46}$

In order to further increase sensitivity, Hoque et al. ${ }^{47}$ measured the urinary DNA methylation status of RASSF1A, RAR $\beta 2$ and APC as well as of GSTP1. All urines from 52 patients with prostate cancer displayed DNA methylation in one or more of these genes. In contrast, urines from non-prostate cancer control subjects were negative for methylation of the same gene profile. In a more recent study, Roupret et al. ${ }^{49}$ reported that these four methylated genes detected prostate cancer with a sensitivity of $86 \%$, at a specificity of $89 \%$.

The above findings suggest that the gene methylation status of urine, serum or ejaculate could complement PSA in the detection of early prostate cancer. Additional markers for prostate cancer are particularly needed for men with PSA concentrations between 4 and $10 \mu \mathrm{g} / \mathrm{L}$ and in those with persistently elevated PSA but negative biopsy. In the latter situation, DNA methylation profiles could be used to stratify men into high risk or low risk groups for either repeated biopsy or surveillance.

Rather than using fluids, Jeronimo et al. ${ }^{48}$ measured the relative level of methylated GSTP1 DNA, i.e. ratio of GSTP1 to MYOD1 methylation in sextant prostate biopsy samples. In this prospective study on 21 patients with elevated PSA levels, 11 had histological confirmation of prostate cancer, while the other 10 had no histological evidence of prostate cancer. The median ratio of GSTP1 to MYOD1 methylation in the biopsy samples was 410 for patients with prostate cancer compared to 0 for those without evidence of prostate cancer. Using an arbitrary cut-off point of 10.0, the authors correctly predicted the histological diagnosis of prostate cancer in 10/11 (90.9\%) of the biopsies from patients with prostate cancer and excluded prostate cancer in all 10 patients whose biopsy displayed no evidence of cancer. Overall, DNA methylation analysis yielded a sensitivity of $90.9 \%$, at a specificity of $100 \%$ with a positive predictive value of $100 \%$ for detecting prostate cancer.

If these results are confirmed, quantitation of GSTP1 methylation could be of value in differentiating between nonmalignant hyperplastic lesions and prostate cancer in biopsy 
samples, and thus could complement the routine pathological examination of prostate tissue.

\subsubsection{Breast cancer}

Currently available serum biomarkers such as CA 15-3 and CEA are of little value for the early detection of breast cancer. In an attempt to establish molecular diagnostic biomarkers for this malignancy, Lewis et al. ${ }^{61}$ measured DNA promoter methylation of RASSF1, APC, H-cadherin, RAR $\beta 2$ and cyclin D2 genes in fine needle biopsy samples from 27 breast cancer patients and 55 unaffected women, whose risk of breast cancer had been defined using a number of established criteria. Methylation of the cyclin D2 gene was found in $57 \%$ of the tumour tissues but not in any benign breast tissues and in the breast tissue of only one of the unaffected women. RAR $\beta 2$ gene methylation was detected in $32 \%$ of benign breast specimens from cancer patients but in only $9 \%$ of similar samples from unaffected women. Significantly, DNA promoter methylation of RASSF1 and APC was found more frequently $(70 \%$ and $56 \%$, respectively) in breast tissues from unaffected women at increased risk of breast cancer than in those with low or intermediate risk of breast cancer $(29 \%$ and $20 \%, p=0.04$ and $p=0.03)$. Determination of the DNA methylation status of RASSF1 and APC promoters might thus be useful for identifying women with benign breast disease at increased risk of developing breast cancer. On the other hand, since cyclin D2 methylation appeared to be found almost exclusively in breast cancer, it might be exploited for the early diagnosis of breast cancer, especially if it could be detected in serum or nipple aspirate fluid (NAF). ${ }^{61}$

In another study on breast cancer, Krassenstein et al. ${ }^{50}$ compared DNA promoter methylation of RAR $\beta 2$, GSTP1, $p 16^{\text {INK4A }}, p 14^{\text {ARF }}$, RASSF1 and DAP kinase in 22 matched specimens of tumour tissue, normal tissue and NAF. NAF was also obtained from five healthy women as well as fibrocystic breast tissue from five additional women. Hypermethylation of at least one of these genes was detected in all 22 cancers, and an identical gene hypermethylation pattern was present in $18 / 22(82 \%)$ of matched NAFs. In contrast, DNA hypermethylation was not detected in benign breast tissue or in NAF from healthy women.

Dulaimi et al. ${ }^{28}$ measured DNA promoter methylation of RASSF1, APC and DAPK in 34 breast cancers and found hypermethylation of at least one of these genes in 32 (94\%) of the samples investigated. Of these 32 patients, sera were also positive for promoter hypermethylation in 26 (76\%). In contrast, hypermethylation of RASSF1, APC or DAPK was not found in any of 6 normal specimens of breast cancer, 6 inflammatory breast tissue lesions, and 20 sera from healthy subjects or in 8 sera from patients with undefined inflammatory diseases. Measurement of gene hypermethylation in NAF or sera may thus be a potential test for aiding the early detection of breast cancer.

Hoque et al., ${ }^{62}$ using plasma, determined the DNA methylation status of APC, GSTP1, RASSF1A and RAR $\beta 2$ in women with breast cancer and controls. It was unclear if the control group was age matched with the breast cancer patients. DNA promoter methylation of at least one of the four genes was present in 29/47 samples from cancer patients (sensitivity, $62 \%$ ) but in only $5 / 38$ control samples (specificity, $87 \%$ ).
These preliminary findings on plasma suggest that DNAmethylated genes may be superior to CA $15-3$ as markers for breast cancer. If the above results are confirmed, methylation of specific genes might be used as an adjunct to mammography in screening for breast cancer. Thus, women found to be DNA methylation-positive for specific genes but to be mammographically negative might undergo intensive follow-up or magnetic resonance imaging (MRI) investigations.

\subsubsection{Ovarian cancer}

CA 125 , the most widely used biomarker in ovarian cancer, is elevated in serum from approximately $80 \%$ of all patients with this malignancy but in only about $50 \%$ of those with early stage or FIGO stage I disease. As well as lacking sensitivity for early stage disease, CA 125 can be increased in most types of adenocarcinomas as well as in multiple types of benign diseases, both gynaecological and non-gynaecological diseases (for review, see Ref. [63]). Similar to the situation with PSA in prostate cancer, this lack of sensitivity and specificity limits the use of CA 125 in screening asymptomatic subjects for ovarian cancer. ${ }^{63}$ Despite this, CA 125 in conjunction with transvaginal ultrasound is currently undergoing evaluation as a screening modality for ovarian cancer. ${ }^{63}$

Ibanez de Caceres et al. ${ }^{51}$ showed that DNA promoter hypermethylation of either the BRCA1 or the RASSFIA gene was present in $34 / 50$ (68\%) of ovarian cancer tissues. The remaining 16 tumours that lacked methylation of either BRCA1 or RASSFIA genes displayed DNA methylation of APC, $p 14, p 16^{\text {INK4A }}$ or DAP. An identical pattern of gene methylation was detected in matched sera from $41 / 50$ (82\%) of patients including 13/17 patients with FIGO stage I disease. Hypermethylation was also found in $28 / 30$ samples of peritoneal fluid from patients with stage Ic-IV disease, including three cases with negative or atypical cytology. Significantly, no DNA hypermethylation of the above genes was found in nonmalignant ovarian tissues, peritoneal fluid or blood from 40 female control subjects.

\subsection{Methylated genes for predicting patient outcome}

For optimum management of patients with cancer, accurate prognostic and predictive factors are necessary. Such factors are particularly important in cancer types that have widely varying outcomes and for which systemic adjuvant therapy may be beneficial, e.g. lymph node-negative breast cancer and stage II colon cancer. In both these situations, prognostic factors may help to differentiate those patients with indolent from those with more aggressive disease. Patients with aggressive disease may then be candidates for treatment with systemic adjuvant therapy, while those with indolent disease may be spared the toxic side-effects and costs of this treatment. Ideally, prognostic factors should be evaluated in the absence of systemic adjuvant therapy. Such a study is best carried out prospectively although a sufficiently high-powered retrospective study lacking bias should also provide reliable data.

In contrast to prognostic biomarkers, predictive biomarkers are factors that are associated with either response or resistance to therapy. ${ }^{64}$ Predictive markers are necessary in 
oncology as cancers of similar histological types may vary widely in their response to a specific therapy. Thus, for most cancer therapies, only a proportion of patients benefit while many needlessly suffer from toxic side-effects. Clearly, for optimum patient management, it is desirable to know the likelihood of response, prior to administration of therapy.

Predictive biomarkers are most conveniently evaluated in either the neoadjuvant or advanced disease settings, i.e. where measurable disease is present. ${ }^{65}$ In the adjuvant setting, predictive markers should be investigated as part of a randomised trial, in which the marker is used to determine response in the treatment arm while a potential prognostic value can be evaluated in the control arm without systemic treatment.

For many of the published investigations that related methylated genes to patient outcome, it was not clear whether a prognostic effect, a predictive effect or a combination of both was assessed. This applies particularly to studies with early cancers that were treated with adjuvant therapy. In the present review, we use the term predicting patient outcome, where it is unclear whether a prognostic or predictive impact is being observed. On the other hand, when it is clear that a pure prognostic or predictive effect was found, we use the appropriate term. The use of methylated genes for aiding prognosis and therapy prediction has been most extensively investigated in breast and brain cancers.

\subsubsection{Breast cancer}

One of the best validated methylated genes for predicting outcome is PITX2 in patients with early breast cancer. Using DNA methylation arrays, Maier et al. $^{66}$ investigated the potential ability of 117 candidate genes to predict outcome in 109 lymph node-negative ER-positive breast cancers treated with adjuvant tamoxifen. Of the 117 genes investigated, methylation of the upstream promoter region of the PITX2 gene gave the strongest correlation with metastasis-free survival. The ability of the microarray method to determine outcome was confirmed with a quantitative DNA methylation assay. ${ }^{66}$

The relationship between PITX2 DNA methylation and outcome in lymph node-negative ER-positive breast cancer patients treated with adjuvant tamoxifen was subsequently validated in two independent multicentre studies. The first of these involved extracts of frozen tumours from 236 women treated at five different European centres, ${ }^{66}$ while the second used paraffin-embedded tumour tissue from 399 patients treated at 10 European centres. ${ }^{67}$ Based on the results from these two studies, PITX2 DNA methylation is a potential biomarker for predicting outcome in patients with newly diagnosed lymph node-negative steroid hormone receptorpositive breast cancer treated with tamoxifen monotherapy. ${ }^{67}$

As well as predicting outcome following treatment with adjuvant tamoxifen, hypermethylation of the PITX2 gene has also been associated with both prognosis in systemically untreated lymph node-negative steroid hormone receptor-positive breast cancer ${ }^{68}$ and risk of developing disease recurrence following treatment of node-positive oestrogen receptor-positive patients with adjuvant anthracycline-based chemotherapy. ${ }^{69}$

DNA methylation has also been investigated for identifying patients with metastatic breast cancer likely to benefit from specific therapies. Martens et al., ${ }^{70}$ using a microarraybased technology, investigated the DNA promoter methylation status of 117 genes in steroid hormone receptor-positive tumours from 200 patients with metastatic breast cancer. Of the 117 genes analysed, 10 were found to be significantly associated with objective response to hormone therapy in patients with recurrent breast cancer. The predictive genes included phosphoserine aminotransferase (PSAT), stathmin (STNM1), S100A2, SFN, PRKC $\delta, S Y K$, VTN, GRIN2D, TGFBR2 and COX7A2L. Of these 10 genes, methylation status of the PSAT promoter displayed the strongest association with response. This finding was confirmed using both an independent quantitative DNA methylation assay and quantitative determination of PSAT mRNA.

\subsubsection{Malignant gliomas}

Although relatively rare, malignant gliomas are associated with disproportionately high morbidity and mortality. ${ }^{71}$ Glioblastomas account for $60-70 \%$ of malignant gliomas. The standard therapy for these tumours is surgical resection, to the extent that it is safely feasible, radiotherapy and chemotherapy. ${ }^{71}$ The main chemotherapy drugs used are alkylating agents such as carmustine and temozolomide. These drugs act by binding to multiple sites in genomic DNA, especially the 0-6 position of guanine. ${ }^{72}$ Binding at these sites leads to interstrand cross-linking, cytotoxicity and apoptosis. This binding, however, can be reduced in the presence of MGMT. Levels of MGMT might thus be expected to correlate with sensitivity to alkylating agents. ${ }^{72}$

Expression of the MGMT gene is at least partially controlled by methylation at its promoter region. ${ }^{72}$ In order to test the hypothesis that methylation at the MGMT DNA promoter might affect response to alkylating drugs, Esteller et al. ${ }^{73}$ investigated the relationship between tumour MGMT gene promoter methylation and response to carmustine in 47 consecutive patients with newly diagnosed gliomas. In this preliminary study, MGMT gene promoter methylation was found in 19 (40\%) of the gliomas and was associated with a better response to chemotherapy, greater overall survival and longer time to progression. Furthermore, MGMT promoter methylation was more predictive of outcome following carmustine therapy than tumour grade, Karnofsky performance status or patients age. As an untreated control arm was not included in this study, it was not possible to determine whether MGMT gene methylation status was prognostic, predictive or both for patients with gliomas.

Subsequent work showed that MGMT gene promoter status was associated with outcome in glioblastoma patients treated with an another alkylating agent, i.e. temozolomide. ${ }^{74}$ In this study on 206 patients, the presence of tumour MGMT DNA promoter methylation predicted a favourable outcome, irrespective of therapy administered. For patients whose tumour contained a methylated MGMT promoter, a significant survival advantage was found in those treated with temozolomide and radiotherapy as compared with those who were given only radiotherapy. In the absence of MGMT DNA promoter methylation, there was only a trend for a difference in survival between the treatment groups.

It should be pointed out that in this study, genomic DNA for MGMT promoter methylation testing was carried out on 
Table 3 - Methylated genes shown to predict outcome in cancer.

\begin{tabular}{|c|c|c|c|}
\hline Gene(s) & Malignancy & Adjuvant systemic therapy & Refs. \\
\hline PITX2 & Breast cancer & Tamoxifen & {$[66,67]$} \\
\hline PITX2 & Breast cancer & None & [68] \\
\hline PITX2 & Breast cancer & Anthracyclene-based & [69] \\
\hline PSAT & Breast cancer & Tamoxifen & {$[70]^{\mathrm{a}}$} \\
\hline ESR1 (ER) & Breast cancer & Tamoxifen & [75] \\
\hline MGMT & Glioma & Carmustine, platinum & [73] \\
\hline MGMT & Glioblastoma & Temozolomide & [74] \\
\hline MGMT & Diffuse large B-cell lymphoma & Cyclophosphamide, vincristine, doxorubicin & [76] \\
\hline HOXA9, TMS9, RAR $\beta 1$ & Neuroblastoma & None & [77] \\
\hline p15, E-cadherin & Acute myeloid leukaemia & None & [78] \\
\hline GSTP1, APC, Cyclin D2, GSTP1 & Prostate cancer & None & {$[79,80]^{\mathrm{b}}$} \\
\hline MGMT, APC, ATM, p16, CDH13, RASSF1A & Non-small-cell lung cancer & NS or None & [81-83] \\
\hline HPP1, HLTF & Colorectal & NS & {$[84]^{\mathrm{b}}$} \\
\hline
\end{tabular}

paraffin sections of glioblastoma tissue. Although, tissue was collected prospectively, specimens were obtained from only about half of the patients and were informative in only about two-thirds of the cases analysed. ${ }^{74}$

\subsubsection{Other methylated genes for predicting patient outcome} As summarised in Table 3, several other methylated genes have been investigated for determining outcome in cancer. Almost all these studies, however, contained relatively small numbers of patients, were retrospective in design and have not been validated. Furthermore, for many of these reports, it was unclear whether a prognostic or predictive impact had been observed.

\section{Unresolved Issues in the use of methylated genes as cancer markers}

\subsection{Specificity of gene methylation for malignancy}

The use of methylated genes for risk identification or aiding cancer diagnosis is based on the assumption that methylation at specific sites in the promoter regions of certain genes is confined to malignancy or premalignant lesions. Other factors, however, may affect gene methylation such as aging and benign diseases.

Kwabi-Addo et al. $^{85}$ examined the effect of aging on DNA methylation in non-malignant human prostate tissue. A significant increase in DNA promoter methylation with age was found for several genes including RARß2, RASSF1A and GSTP1. Another gene, i.e. MYOD1 that was shown to undergo age-related changes in colorectal cancer, ${ }^{86}$ however, did not exhibit age-related methylation in normal prostate. ${ }^{85}$ The implication of these findings is that studies investigating a potential diagnostic utility for methylated genes should as a minimum include age-matched controls.

Certain benign diseases, especially benign tumours, may also exhibit altered gene methylation. Little or no research has been carried out in this area but is essential prior to gene methylation assays being recommended for cancer screening and/or diagnostic purposes.

\subsection{Unresolved analytical issues}

A major unresolved analytical issue is the optimum system/ platform to be used for determining gene methylation in the clinical setting. Currently, multiple approaches are available for measuring gene methylation in research laboratories. ${ }^{6,87-89}$ Some of the most commonly used methodologies, together with their advantages and disadvantages are listed in Table 4.

According to the recent National Cancer Institute workshop on the clinical application of methylated DNA sequences as cancer biomarkers, bisulphite sequencing is optimal for the detection of $\mathrm{CpG}$ island methylation of new genes, pyrosequencing is best for quantitation of individual CpG sites while quantitative methylation-specific PCR is best for sensitive detection of methylated alleles. ${ }^{89}$ It is unclear which, if any, of these will be used for routine clinical purposes. Following selection of a specific analytical platform, assays for clinically important methylated genes must be optimised, standardised and must undergo technical validation including evaluation in external quality assurance programmes. ${ }^{110}$

\subsection{Requirement for clinical validation}

It is clear from above that methylated genes are promising biomarkers for aiding the early detection of cancer and for managing patients with diagnosed malignancy. It should, however, be emphasised that virtually all the published studies so far have been small scale and retrospective in design. In order for methylated genes to enter routine clinical use, these preliminary findings must be confirmed in high-level evidence studies such as prospective trials or meta/pooled analysis of individual data from smaller-scale studies. Furthermore, the measurement of methylated genes must be able to provide additional information to that available from existing diagnostic, prognostic and predictive modalities. Most importantly, the additional information must be clinically relevant, i.e. provide information that improves patient outcome, enhances quality of life or leads to reduced health care costs.

In order to accelerate this clinical validation, multicentre collaboration will be necessary and a clear pathway estab- 
Table 4 - Methodologies used for determining DNA methylation pattern, together with their advantages and disadvantages. MS-MPLA, Methylation-specific multiplex ligation-dependent probe amplification; MS-SNuPE, methylation-sensitive single nucleotide primer extension; MB-PCR, methylation binding PCR; MS-FLAG,

methylation-specific fluorescent amplicon generation; MeDIP, methylated DNA immunoprecipitation; DMH/MGAM/RLGS, differentiation methylation hybridisation/

methylated CpG island amplification/restriction land mark genomic screening; MBP, methylation binding protein; MIRA, methylated CpG island recovery assay and MS, mass spectrometry.

\begin{tabular}{|c|c|c|c|c|c|c|c|c|c|c|c|}
\hline $\begin{array}{l}\text { Genome wide } \\
\text { screening } \\
\text { methods }\end{array}$ & $\begin{array}{l}\text { Uni- or } \\
\text { multiplex } \\
\text { or genome- } \\
\text { wide } \\
\text { screening } \\
\text { (U/M/G) }\end{array}$ & $\begin{array}{l}\text { Low or } \\
\text { high } \\
\text { throughput } \\
\text { (L/H) }\end{array}$ & $\begin{array}{l}\text { Methylation } \\
\text { sensitive } \\
\text { restriction }\end{array}$ & $\begin{array}{l}\text { Bisulfite } \\
\text { conversion }\end{array}$ & $\begin{array}{l}\text { Methylated } \\
\text { CpG immuno- } \\
\text { precipitation }\end{array}$ & $\begin{array}{l}\text { Gel based } \\
\text { fragment } \\
\text { detection }\end{array}$ & $\begin{array}{l}\text { Real-time } \\
\text { detection }\end{array}$ & $\begin{array}{l}\text { Array- } \\
\text { based } \\
\text { detection }\end{array}$ & $\begin{array}{l}\text { Ultradeep } \\
\text { sequencer }\end{array}$ & $\begin{array}{l}\text { Costl } \\
(\$ / \$ \$ / \$ \$ 1 \\
\$ \$ \$ \$)\end{array}$ & Refs. \\
\hline $\begin{array}{l}\text { Methylation } \\
\text { sensitive restriction/ } \\
\text { MS-MPLA }\end{array}$ & M & $\mathrm{H}$ & $\mathrm{x}$ & & & $\mathrm{x}$ & & & & $\$$ & {$[86,90]$} \\
\hline $\begin{array}{l}\text { MSP/COBRA/MS- } \\
\text { SNuPE }\end{array}$ & $\mathrm{U}$ & $\mathrm{H}$ & - & $\mathrm{x}$ & & $\mathrm{x}$ & & & & $\$$ & [91-93] \\
\hline $\begin{array}{l}\text { MB-PCR/COMPARE- } \\
\text { MS }\end{array}$ & $\mathrm{U}$ & $\mathrm{H}$ & $\mathrm{x}$ & & $\mathrm{x}$ & & $\mathrm{x}$ & & & $\$ \$$ & {$[94,95]$} \\
\hline $\begin{array}{l}\text { Real time MSP } \\
\text { (Methylight/MS- } \\
\text { FLAG/HeavyMethyl) }\end{array}$ & $\mathrm{U}$ & $\mathrm{H}$ & & $\mathrm{x}$ & & & $\mathrm{x}$ & & & $\$ \$$ & [96-98] \\
\hline $\begin{array}{l}\text { Bisulfite sequencing } \\
\text { /pyrosequencing }\end{array}$ & $\mathrm{U}$ & $\mathrm{M}$ & & $\mathrm{x}$ & & $\mathrm{x}$ & - & & & $\$ \$$ & [99] \\
\hline $\begin{array}{l}\text { Ultradeep bisulfite } \\
\text { sequencing (MeDIP- } \\
\text { seq) }\end{array}$ & G & $\mathrm{L}$ & & $\mathrm{x}$ & & & - & & $\mathrm{x}$ & $\$ \$ \$$ & {$[100]$} \\
\hline DMH/MCAM/RLGS & G & $\mathrm{L}$ & $\mathrm{x}$ & - & & $\mathrm{x}$ & - & $\mathrm{x}$ & & $\$ \$$ & [101-103] \\
\hline $\begin{array}{l}\text { MeDIP/MBP Chip on } \\
\text { Chip/MIRA }\end{array}$ & G & $\mathrm{L}$ & & - & $\mathrm{x}$ & & - & $\mathrm{x}$ & & $\$ \$$ & [104-106] \\
\hline $\begin{array}{l}\text { Bisulphite converted } \\
\text { DNA on array }\end{array}$ & G/M & $\mathrm{L}$ & & $\mathrm{x}$ & & & - & $\mathrm{x}$ & & $\$ \$$ & {$[107]$} \\
\hline $\begin{array}{l}\text { Bisulphite converted } \\
\text { DNA on MS }\end{array}$ & $\mathrm{M} / \mathrm{U}$ & $\mathrm{L} / \mathrm{H}$ & & $\mathrm{x}$ & & & - & & & $\$ \$$ & {$[108,109]$} \\
\hline
\end{tabular}


lished for validation. In this context, it should be mentioned that the US National Cancer Institute has formed an organisation known as the Early Detection Research Network (EDRN). ${ }^{111,112}$ The aim of this group is to bring together the experts from academia and industry in order to promote biomarker discovery and validation, while also helping transfer of this knowledge to clinical practice.

The EDRN network has also published criteria for the development and validation of new markers for the early detection of cancer. The first phase involves preclinical exploration to help identify promising markers. Next is the development of an assay and validation phase necessary to test the ability of the assay to detect established disease. The third is a retrospective and longitudinal phase to assess the new marker's ability to diagnose preclinical disease and to define a "screen positive" rule. Following this, prospective screening is carried out to identify the extent and characteristics of disease detected by the test, as well as the false-positive rate. In the final phase, a definite trial, such as a prospective randomised study, is performed to evaluate the value of screening on the burden of disease in the general population. These steps that are endorsed by the PathoBiology Group of the European Organisation for Research and Treatment of Cancer (EORTC) ${ }^{110}$ should now be implemented to evaluate the promising new diagnostic biomarkers emerging from the research on gene methylation in cancer.

\section{Conclusion}

Increasing data suggest that DNA methylation measurements of the promoter regions of specific genes have the potential to supply additional or superior information to that available from the existing cancer markers. These early finding now requires validation, initially in retrospective studies but ultimately in large prospective clinical studies. In addition to clinical validation, assays for methylated genes must be robust, simple, standardised, evaluated in external quality assurance schemes and made available at affordable costs. Only then, can patients expect to benefit from measurement of these markers.

Finally, with the approaching era of personalised medicine, the link between biomarkers and therapy will be enhanced. ${ }^{113,114}$ In this context, it should be stated that a number of therapies directed against methylated genes are now in clinical use. ${ }^{8}$ Thus, the hypomethylating agents 5-azacytidine and 5'aza-2'deoxycytidine have been approved for the treatment of specific leukaemia and the myelodysplastic syndrome. While these demethylating agents are non-specific with respect to their target gene(s), the aim in the future will be to develop drugs that target specific methylated genes causally involved in malignancy such as tumour suppressor genes and genes encoding miRNAs. ${ }^{8,9}$ Whether specific DNA methylation patterns in tumour cells will be able to predict response to these agents remains to be determined.

\section{Conflict of interest statement}

J.F., J.M. and M.S. are inventors on patent related to outcome predictions in breast cancer.

\section{Acknowledgements}

Work of the authors included in this manuscript was funded by the European Union 6th Framework Programme (LSHC-CT2003-504586) and European Union 6th Framework Programme CHEMORES.

\section{R E F E R E N C E S}

1. Duffy MJ. Role of tumor markers in patients with solid cancers: a critical review. Eur J Intern Med 2007;18:175-84.

2. Thomas CM, Sweep CG. Serum tumor markers: past, state of the art, and future. Int J Biol Markers 2001;16:73-86.

3. Hahn WC, Weinberg RA. Rules for making human tumor cells. New Engl J Med 2002;347:1593-603.

4. Vogelstein B, Kinzler KW. Cancer genes and the pathways they control. Nat Med 2004;10:789-99.

5. Anker P, Mulcahy H, Stroun M. Circulating nucleic acids in plasma and serum as a noninvasive investigation for cancer: time for large-scale clinical studies? Int J Cancer 2003;103:149-52.

6. Chin L, Gray JW. Translating insights from the cancer genome into clinical practice. Nature 2008;452:553-63.

7. Sidransky D. Nucleic acid-based methods for the detection of cancer. Science 1997;278:1054-9.

8. Esteller M. Epigenetics in cancer. New Engl J Med 2008;358:1148-59.

9. Jones PA, Baylin SB. The epigenomics of cancer. Cell 2007;128:683-92.

10. Laird PW. The power and the promise of DNA methylation markers. Nat Rev Cancer 2003;3:253-66.

11. Widschwendter $\mathrm{M}$, Jones PA. DNA methylation and breast carcinogenesis. Oncogene 2002;21:5462-82.

12. Costello JF, Fruhwald MC, Smiraglia DJ, et al. Aberrant CpGisland methylation has non-random and tumour-typespecific patterns. Nat Genet 2000;24:132-8.

13. Momparler RL. Cancer epigenetics. Oncogene 2003;22:6479-83.

14. Wong DJ, Barrett MT, Stoger R, et al. P16INK4a promoter is hypermethylated at a high frequency in esophageal adenocarcinomas. Cancer Res 1997;57:2619-22.

15. Wong DJ, Paulson TG, Prevo LJ, et al. P16(INK4a) lesions are common, early abnormalities that undergo clonal expansion in Barrett's metaplastic epithelium. Cancer Res 2001;61:8284-9.

16. Belinsky SA, Nikula KJ, Palmisano WA, et al. Aberrant methylation of p16(INK4a) is an early event in lung cancer and a potential biomarker for early diagnosis. Proc Natl Acad Sci U S A 1998;95:11891-6.

17. Nuovo GJ, Plaia TW, Belinsky SA, et al. In situ detection of the hypermethylation-induced inactivation of the p16 gene as an early event in oncogenesis. Proc Natl Acad Sci USA 1999;96:12754-9.

18. Esteller M, Tortola S, Toyota M, et al. Hypermethylationassociated inactivation of p14(ARF) is independent of p16(INK4a) methylation and p53 mutational status. Cancer Res 2000;60:129-33.

19. Esteller M, Sparks A, Toyota M, et al. Analysis of adenomatous polyposis coli promoter hypermethylation in human cancer. Cancer Res 2000;60:4366-71.

20. Esteller M, Toyota M, Sanchez-Cespedes M, et al. Inactivation of the DNA repair gene 06-methylguanine-DNA methyltransferase by promoter hypermethylation is associated with $\mathrm{G}$ to A mutations in K-ras in colorectal tumorigenesis. Cancer Res 2000;60:2368-71. 
21. Fleisher AS, Esteller M, Harpaz N, et al. Microsatellite instability in inflammatory bowel disease-associated neoplastic lesions is associated with hypermethylation and diminished expression of the DNA mismatch repair gene, hMLH1. Cancer Res 2000;60:4864-8.

22. Esteller M, Catasus L, Matias-Guiu X, et al. HMLH1 promoter hypermethylation is an early event in human endometrial tumorigenesis. Am J Pathol 1999;155:1767-72.

23. Brooks JD, Weinstein M, Lin X, et al. CG island methylation changes near the GSTP1 gene in prostatic intraepithelial neoplasia. Cancer Epidemiol Biomarkers Prev 1998;7:531-6.

24. Jeronimo C, Henrique R, Hoque MO, et al. A quantitative promoter methylation profile of prostate cancer. Clin Cancer Res 2004;10:8472-8.

25. Harder J, Opitz OG, Brabender J, et al. Quantitative promoter methylation analysis of hepatocellular carcinoma, cirrhotic and normal liver. Int J Cancer 2008;122:2800-4.

26. Umbricht CB, Evron E, Gabrielson E, et al. Hypermethylation of 14-3-3 sigma (stratifin) is an early event in breast cancer. Oncogene 2001;20:3348-53.

27. Honorio S, Agathanggelou A, Schuermann M, et al. Detection of RASSF1A aberrant promoter hypermethylation in sputum from chronic smokers and ductal carcinoma in situ from breast cancer patients. Oncogene 2003;22: 147-50.

28. Dulaimi E, Hillinck J, Ibanez de Caceres I, et al. Tumor suppressor gene promoter hypermethylation in serum of breast cancer patients. Clin Cancer Res 2004;10:6189-93.

29. Feng Q, Balasubramanian A, Hawes SE, et al. Detection of hypermethylated genes in women with and without cervical neoplasia. J Natl Cancer Inst 2005;97:273-82.

30. Lafata JE, Simpkins J, Lamerato L, et al. The economic impact of false-positive cancer screens. Cancer Epidemiol Biomarkers Prev 2004;13:2126-32.

31. Kane MF, Loda M, Gaida GM, et al. Methylation of the hMLH1 promoter correlates with lack of expression of hMLH1 in sporadic colon tumors and mismatch repair-defective human tumor cell lines. Cancer Res 1997;57:808-11.

32. Toyota M, Ahuja N, Suzuki H, et al. Aberrant methylation in gastric cancer associated with the CpG island methylator phenotype. Cancer Res 1999;59:5438-42.

33. Eads CA, Lord RV, Wickramasinghe K, et al. Epigenetic patterns in the progression of esophageal adenocarcinoma. Cancer Res 2001;61:3410-8.

34. Shen L, Ahuja N, Shen Y, et al. DNA methylation and environmental exposures in human hepatocellular carcinoma. J Natl Cancer Inst 2002;94:755-61.

35. Esteller M, Corn PG, Baylin SB, et al. A gene hypermethylation profile of human cancer. Cancer Res 2001;61:3225-9.

36. Paz MF, Fraga MF, Avila S, et al. A systematic profile of DNA methylation in human cancer cell lines. Cancer Res 2003;63:1114-21.

37. Hainaut P, Hollstein M. P53 and human cancer: the first ten thousand mutations. Adv Cancer Res 2000;77:81-137.

38. Laurent-Puig P, Beroud C, Soussi T. APC gene: database of germline and somatic mutations in human tumors and cell lines. Nucleic Acids Res 1998;26:269-70.

39. Belinsky SA. Gene-promoter hypermethylation as a biomarker in lung cancer. Nat Rev Cancer 2004;4:707-17.

40. Palmisano WA, Divine KK, Saccomanno G, et al. Predicting lung cancer by detecting aberrant promoter methylation in sputum. Cancer Res 2000;60:5954-8.

41. Kersting M, Friedl C, Kraus A, et al. Differential frequencies of p16(INK4a) promoter hypermethylation, p53 mutation, and $\mathrm{K}$-ras mutation in exfoliative material mark the development of lung cancer in symptomatic chronic smokers. J Clin Oncol 2000;18:3221-9.
42. Goessl C, Krause H, Muller M, et al. Fluorescent methylation-specific polymerase chain reaction for DNAbased detection of prostate cancer in bodily fluids. Cancer Res 2000;60:5941-5.

43. Goessl C, Muller M, Straub B, et al. DNA alterations in body fluids as molecular tumor markers for urological malignancies. Eur Urol 2002;41:668-76.

44. Li LC, Carroll PR, Dahiya R. Epigenetic changes in prostate cancer: implication for diagnosis and treatment. J Natl Cancer Inst 2005;97:103-15.

45. Suh CI, Shanafelt T, May DJ, et al. Comparison of telomerase activity and GSTP1 promoter methylation in ejaculate as potential screening tests for prostate cancer. Mol Cell Probe 2000;14:211-7.

46. Goessl C, Muller M, Heicappell R, et al. DNA-based detection of prostate cancer in urine after prostatic massage. Urology 2001;58:335-8.

47. Hoque MO, Topaloglu O, Begum S, et al. Quantitative methylation-specific polymerase chain reaction gene patterns in urine sediment distinguish prostate cancer patients from control subjects. J Clin Oncol 2005;23:6569-75.

48. Jeronimo C, Usadel H, Henrique R, et al. Quantitation of GSTP1 methylation in non-neoplastic prostatic tissue and organ-confined prostate adenocarcinoma. J Natl Cancer Inst 2001;93:1747-52.

49. Roupret M, Hupertan V, Yates DR, et al. Molecular detection of localized prostate cancer using quantitative methylationspecific PCR on urinary cells obtained following prostate massage. Clin Cancer Res 2007;13:1720-5.

50. Krassenstein R, Sauter E, Dulaimi E, et al. Detection of breast cancer in nipple aspirate fluid by CpG island hypermethylation. Clin Cancer Res 2004;10:28-32.

51. Ibanez de Caceres I, Battagli C, Esteller M, et al. Tumor cellspecific BRCA1 and RASSF1A hypermethylation in serum, plasma, and peritoneal fluid from ovarian cancer patients. Cancer Res 2004;64:6476-81.

52. Muller HM, Oberwalder M, Fiegl H, et al. Methylation changes in faecal DNA: a marker for colorectal cancer screening? Lancet 2004;363:1283-5.

53. Petko Z, Ghiassi M, Shuber A, et al. Aberrantly methylated CDKN2A, MGMT, and MLH1 in colon polyps and in fecal DNA from patients with colorectal polyps. Clin Cancer Res 2005;11:1203-9.

54. Lofton-Day C, Model F, Devos T, et al. DNA methylation biomarkers for blood-based colorectal cancer screening. Clin Chem 2008;54:414-23.

55. Dulaimi E, Uzzo RG, Greenberg RE, et al. Detection of bladder cancer in urine by a tumor suppressor gene hypermethylation panel. Clin Cancer Res 2004;10:1887-93.

56. Friedrich MG, Weisenberger DJ, Cheng JC, et al. Detection of methylated apoptosis-associated genes in urine sediments of bladder cancer patients. Clin Cancer Res 2004;10:7457-65.

57. Keller T, Bitterlich N, Hilfenhaus S, et al. Tumour markers in the diagnosis of bronchial carcinoma: new options using fuzzy logic-based tumour marker profiles. J Cancer Res Clin Oncol 1998;124:565-74.

58. Watine J. Prognostic evaluation of primary non-small cell lung carcinoma patients using biological fluid variables. A systematic review. Scand J Clin Lab Invest 2000;60:259-73.

59. Hernandez J, Thompson IM. Prostate-specific antigen: a review of the validation of the most commonly used cancer biomarker. Cancer 2004;101:894-904.

60. Lilja H, Ulmert D, Vickers AJ. Prostate-specific antigen and prostate cancer: prediction, detection and monitoring. Nat Reu Cancer 2008;8:268-78.

61. Lewis CM, Cler LR, Bu DW, et al. Promoter hypermethylation in benign breast epithelium in relation to predicted breast cancer risk. Clin Cancer Res 2005;11:166-72. 
62. Hoque MO, Feng Q, Toure P, et al. Detection of aberrant methylation of four genes in plasma DNA for the detection of breast cancer. J Clin Oncol 2006;24:4262-9.

63. Duffy MJ, Bonfrer JM, Kulpa J, et al. CA125 in ovarian cancer: European Group on Tumor Markers guidelines for clinical use. Int J Gynecol Cancer 2005;15:679-91.

64. Duffy MJ. Predictive markers in breast and other cancers: a review. Clin Chem 2005;51:494-503.

65. Lonning PE. Study of suboptimum treatment response: lessons from breast cancer. Lancet Oncol 2003;4:177-85.

66. Maier S, Nimmrich I, Koenig T, et al. DNA-methylation of the homeodomain transcription factor PITX2 reliably predicts risk of distant disease recurrence in tamoxifen-treated, node-negative breast cancer patients - technical and clinical validation in a multi-centre setting in collaboration with the European Organisation for Research and Treatment of Cancer (EORTC) PathoBiology group. Eur J Cancer 2007;43:1679-86.

67. Harbeck N, Nimmrich I, Hartmann A, et al. Multicenter study using paraffin-embedded tumor tissue testing PITX2 DNA methylation as a marker for outcome prediction in tamoxifen-treated, node-negative breast cancer patients. J Clin Oncol 2008;26:5036-42.

68. Nimmrich I, Sieuwerts AM, Meijer-van Gelder ME, et al. DNA hypermethylation of PITX2 is a marker of poor prognosis in untreated lymph node-negative hormone receptor-positive breast cancer patients. Breast Cancer Res Treat 2008;111:429-37.

69. Hartmann O, Spyratos F, Harbeck N, et al. DNA methylation markers predict outcome in node-positive, estrogen receptor-positive breast cancer patients treated with adjuvant anthracyclene-based chemotherapy. Clin Cancer Res 2009;15:307-14.

70. Martens JW, Nimmrich I, Koenig T, et al. Association of DNA methylation of phosphoserine aminotransferase with response to endocrine therapy in patients with recurrent breast cancer. Cancer Res 2005;65:4101-17.

71. Wen PY, Kesari S. Malignant gliomas in adults. New Engl J Med 2008;359:492-507.

72. Pegg AE. Repair of O(6)-alkylguanine by alkyltransferases. Mutat Res 2000;462:83-100.

73. Esteller M, Garcia-Foncillas J, Andion E, et al. Inactivation of the DNA-repair gene MGMT and the clinical response of gliomas to alkylating agents. New Engl J Med 2000;343:1350-4.

74. Hegi ME, Diserens AC, Gorlia T, et al. MGMT gene silencing and benefit from temozolomide in glioblastoma. New Engl $J$ Med 2005;352:997-1003.

75. Widschwendter M, Siegmund KD, Muller HM, et al. Association of breast cancer DNA methylation profiles with hormone receptor status and response to tamoxifen. Cancer Res 2004;64:3807-13.

76. Esteller M, Gaidano G, Goodman SN, et al. Hypermethylation of the DNA repair gene $\mathrm{O}(6)$-methylguanine DNA methyltransferase and survival of patients with diffuse large B-cell lymphoma. J Natl Cancer Inst 2002;94:26-32.

77. Alaminos M, Davalos V, Cheung NK, et al. Clustering of gene hypermethylation associated with clinical risk groups in neuroblastoma. J Natl Cancer Inst 2004;96:1208-19.

78. Shimamoto T, Ohyashiki JH, Ohyashiki K. Methylation of p15(INK4b) and E-cadherin genes is independently correlated with poor prognosis in acute myeloid leukemia. Leuk Res 2005;29:653-9.

79. Bastian PJ, Palapattu GS, Lin X, et al. Preoperative serum DNA GSTP1 CpG island hypermethylation and the risk of early prostate-specific antigen recurrence following radical prostatectomy. Clin Cancer Res 2005;11:4037-43.

80. Rosenbaum E, Hoque MO, Cohen Y, et al. Promoter hypermethylation as an independent prognostic factor for relapse in patients with prostate cancer following radical prostatectomy. Clin Cancer Res 2005;11:8321-5.

81. Brabender J, Usadel H, Metzger R, et al. Quantitative O(6)methylguanine DNA methyltransferase methylation analysis in curatively resected non-small cell lung cancer: associations with clinical outcome. Clin Cancer Res 2003;9:223-7.

82. Safar AM, Spencer 3rd H, Su X, et al. Methylation profiling of archived non-small cell lung cancer: a promising prognostic system. Clin Cancer Res 2005;11:4400-5.

83. Brock MV, Hooker CM, Ota-Machida E, et al. DNA methylation markers and early recurrence in stage I lung cancer. N Engl J Med 2008;358:1118-28.

84. Wallner M, Herbst A, Behrens A, et al. Methylation of serum DNA is an independent prognostic marker in colorectal cancer. Clin Cancer Res 2006;12:7347-52.

85. Kwabi-Addo B, Chung W, Shen L, et al. Age-related DNA methylation changes in normal human prostate tissues. Clin Cancer Res 2007;13:3796-802.

86. Issa JP, Ottaviano YL, Celano P, et al. Methylation of the oestrogen receptor CpG island links ageing and neoplasia in human colon. Nat Genet 1994;7:536-40.

87. Frommer M, McDonald LE, Millar DS, et al. A genomic sequencing protocol that yields a positive display of 5 methylcytosine residues in individual DNA strands. Proc Natl Acad Sci USA 1992;89:1827-31.

88. Fraga MF, Esteller M. DNA methylation: a profile of methods and applications. Biotechniques 2002;33:636-49.

89. Kagan J, Srivastava S, Barker PE, et al. Towards clinical application of methylated DNA sequences as cancer biomarkers: A Joint NCI's EDRN and NIST Workshop on Standards, Methods, Assays, Reagents and Tools. Cancer Res 2007;67:4545-9.

90. Henken FE, Wilting SM, Overmeer RM, et al. Sequential gene promoter methylation during HPV-induced cervical carcinogenesis. Brit J Cancer 2007;97:1457-64.

91. Herman JG, Graff JR, Myohanen S, et al. Methylation-specific PCR: a novel PCR assay for methylation status of CpG islands. Proc Natl Acad Sci USA 1996;93:9821-6.

92. Xiong Z, Laird PW. COBRA: a sensitive and quantitative DNA methylation assay. Nucleic Acids Res 1997;25:2532-4.

93. Gonzalgo ML, Jones PA. Rapid quantitation of methylation differences at specific sites using methylation-sensitive single nucleotide primer extension (Ms-SNuPE). Nucleic Acids Res 1997;25:2529-31.

94. Gebhard C, Schwarzfischer L, Pham TH, et al. Rapid and sensitive detection of CpG-methylation using methylbinding (MB)-PCR. Nucleic Acids Res 2006;34:e82.

95. Yegnasubramanian S, Lin X, Haffner MC, et al. Combination of methylated-DNA precipitation and methylation-sensitive restriction enzymes (COMPARE-MS) for the rapid, sensitive and quantitative detection of DNA methylation. Nucleic Acids Res 2006;34:e19.

96. Eads CA, Danenberg KD, Kawakami K, et al. MethyLight: a high-throughput assay to measure DNA methylation. Nucleic Acids Res 2000;28:E32.

97. Bonanno C, Shehi E, Adlerstein D, et al. MS-FLAG, a novel real-time signal generation method for methylation-specific PCR. Clin Chem 2007;53:2119-27.

98. Cottrell SE, Distler J, Goodman NS, et al. A real-time PCR assay for DNA-methylation using methylation-specific blockers. Nucleic Acids Res 2004;32:e10.

99. Uhlmann K, Brinckmann A, Toliat MR, et al. Evaluation of a potential epigenetic biomarker by quantitative methylsingle nucleotide polymorphism analysis. Electrophoresis 2002;23:4072-9.

100. Taylor KH, Kramer RS, Davis JW, et al. Ultradeep bisulfite sequencing analysis of DNA methylation patterns in 
multiple gene promoters by 454 sequencing. Cancer Res 2007;67:8511-8.

101. Huang TH, Perry MR, Laux DE. Methylation profiling of CPG islands in human breast cancer cells. Hum Mol Genet 1999;8:459-70.

102. Estecio MR, Yan PS, Ibrahim AE, et al. High-throughput methylation profiling by MCA coupled to CpG island microarray. Genome Res 2007;17:1529-36.

103. Hayashizaki Y, Hirotsune S, Okazaki Y, et al. Restriction landmark genomic scanning method and its various applications. Electrophoresis 1993;14:251-8.

104. Wilson IM, Davies JJ, Weber M, et al. Epigenomics: mapping the methylome. Cell Cycle 2006;5:155-8.

105. Ballestar E, Paz MF, Valle L, et al. Methyl-CpG binding proteins identify novel sites of epigenetic inactivation in human cancer. Embo J 2003;22:6335-45.

106. Rauch T, Li H, Wu X, et al. MIRA-assisted microarray analysis, a new technology for the determination of DNA methylation patterns, identifies frequent methylation of homeodomain-containing genes in lung cancer cells. Cancer Res 2006;66:7939-47.

107. Adorjan P, Distler J, Lipscher E, et al. Tumour class prediction and discovery by microarray-based DNA methylation analysis. Nucleic Acids Res 2002;30:e21.

108. Coolen MW, Statham AL, Gardiner-Garden M, et al. Genomic profiling of CpG methylation and allelic specificity using quantitative high-throughput mass spectrometry: critical evaluation and improvements. Nucleic Acids Res 2007;35:e119.

109. Schatz P, Distler J, Berlin K, et al. Novel method for high throughput DNA methylation marker evaluation using PNAprobe library hybridization and MALDI-TOF detection. Nucleic Acids Res 2006;34:e59.

110. Sweep FC, Fritsche HA, Gion M, et al. Considerations on development, validation, application, and quality control of immuno(metric) biomarker assays in clinical cancer research: an EORTC-NCI working group report. Int $J$ Oncol 2003;23:1715-26.

111. Pepe MS, Etzioni R, Feng Z, et al. Phases of biomarker development for early detection of cancer. J Natl Cancer Inst 2001;93:1054-61.

112. Pepe MS, Feng Z, Janes H, et al. Pivotal evaluation of the accuracy of a biomarker used for classification or prediction: standards for study design. J Natl Cancer Inst 2008;100:1432-8.

113. Foekens JA, Wang Y, Martens JW, et al. The use of genomic tools for the molecular understanding of breast cancer and to guide personalized medicine. Drug Discou Today 2008;13:481-7.

114. Duffy MJ, Crown J. A personalized approach to cancer treatment: how biomarkers can help. Clin Chem 2008;54:1770-9. 